Applied Physiology, Nutrition, and Metabolism Physiologie appliquée, nutrition et métabolisme

\title{
Exercise Prescription to Reverse Frailty
}

\begin{tabular}{|r|l|}
\hline Journal: & Applied Physiology, Nutrition, and Metabolism \\
\hline Manuscript ID & apnm-2016-0226.R1 \\
\hline Manuscript Type: & Clinical Corner \\
\hline Complete List of Authors: & $\begin{array}{l}\text { Bray, Nick; University of British Columbia, School of Health and Exercise } \\
\text { Sciences } \\
\text { Smart, Rowan; University of British Columbia, School of Health and } \\
\text { Exercise Sciences } \\
\text { Jakobi, Jennifer; University of British Columbia, School of Health and } \\
\text { Exercise Sciences } \\
\text { Jones, Gareth; University of British Columbia, School of Health and } \\
\text { Exercise Sciences }\end{array}$ \\
\hline Keyword: & $\begin{array}{l}\text { aging, frailty, exercise prescription < exercise, exercise training < exercise, } \\
\text { resistance exercise < exercise }\end{array}$ \\
\hline &
\end{tabular}

\section{SCHOLARONE ${ }^{\text {m }}$}

Manuscripts 
Title:

Exercise Prescription to Reverse Frailty

Authors:

Nick W. Bray B.Kin

Rowan R. Smart BHK

Jennifer M. Jakobi PhD

Gareth R. Jones PhD

School of Health and Exercise Sciences, University of British Columbia Okanagan, Kelowna, BC, V1V 1V7

Corresponding author:

Gareth R. Jones

Health and Exercise Sciences

UBC Okanagan

Kelowna, BC

V1V 1V7

gareth.jones@ubc.ca

(250)-807-8102 
Frailty is a clinical geriatric syndrome caused by physiological deficits across multiple systems. These deficits make it challenging to sustain homeostasis required for the demands of everyday life. Exercise is likely the best therapy to reverse frailty status. Literature to-date suggests prefrail older adults, those with 1-2 deficits on the Cardiovascular Health Study-Frailty Phenotype (CHS-frailty phenotype) should exercise 2-3 times a week, for 45-60 minutes. Aerobic, resistance, flexibility, and balance training components should be incorporated but resistance and balance activities should be emphasized. On the other hand, frail (CHS-frailty phenotype $\geq 3$ physical deficits) older adults should exercise 3 times per week, for 30-45 minutes for each session with an emphasis on aerobic training. During aerobic, balance and flexibility training both frail and pre-frail older adults should work at an intensity equivalent to a rating of perceived exertion of 3-4 ("somewhat hard") on the CR-10 scale. Resistance training intensity should be based on a percentage of 1-RM. Program onset should occur at 55\% of 1-RM (endurance) and progress to higher intensities of $80 \%$ of 1-RM (strength) to maximize functional gains. Exercise is the medicine to reverse or mitigate frailty, preserve quality of life and restore independent functioning in older adults at risk of frailty.

\section{Key Words}

Aging, Frailty, Exercise Prescription, Exercise Training, Resistance Exercise, Exercise Recommendations 
La fragilité est un syndrome gériatrique clinique causée par les déficits physiologiques sur plusieurs systèmes. Ces déficits font qu'il est difficile de maintenir l'homéostasie requis pour les demandes de la vie quotidienne. L'exercice est probablement la meilleure thérapie pour renverser l'état de fragilité. La littérature suggère à jour pré-personnes âgées frêles, ceux avec les déficits 1-2 Santé cardiovasculaire phénotype Study-Frailty (SHC-phénotype de fragilité) devrait exercer 2-3 fois par semaine, pendant 45-60 minutes. Aérobie, résistance, de la souplesse et de l'équilibre des éléments de formation devraient être incorporés, mais la résistance et l'équilibre des activités devrait être soulignée. D'autre part, frêles (CHS-fragilité phénotype $\geq 3$ déficits physiques) les adultes plus âgés doivent exercer 3 fois par semaine, pendant 30-45 minutes pour chaque session en mettant l'accent sur l'entraînement aérobie. Au cours d'aérobie, l'équilibre et la souplesse de la formation à la fois fragile et pré-personnes âgées frêles devraient travailler à une intensité équivalente à une perception de l'effort de 3-4 ("quelque peu difficile ") sur la CR-10 échelle. Résistance l'intensité de la formation devrait être fondée sur un pourcentage de 1-RM. Commencement du programme devrait se faire à $55 \%$ de $1 \mathrm{RM}$ (endurance) et des progrès réalisés à des intensités plus élevées de $80 \%$ des 1RM (force) afin de maximiser les gains fonctionnelle. L'exercice est la médecine pour enrayer ou d'atténuer la fragilité, à préserver la qualité de vie et rétablir un fonctionnement indépendant chez les adultes plus âgés à risque de fragilité.

\section{Mots clés}

Vieillissement, fragilité, prescription d'activité physique, entraînement physique, exercice de musculation, exercice recommandations 


\section{$\underline{\text { Introduction }}$}

Frailty is a geriatric syndrome distinct from disability and comorbidity. Although poorly defined, frailty manifests as an accumulation of physiological deficits, inclusive of chronic health conditions and physical disability. Independent of age, frailty is predictive of mortality, hospitalization, institutionalization, falls, and worsening health status (de Labra et al. 2015). Upwards of 1 million Canadians are considered frail; this value will continue to climb as the population matures (Hoover et al. 2013).

\section{$\underline{\text { Measuring Frailty }}$}

Two common assessment tools used to determine frailty status include; the Clinical Frailty Scale (CFS) (Rockwood et al. 2005), and the Cardiovascular Health Study-Frailty Phenotype (CHSfrailty phenotype) (Fried et al. 2001). Although these scales are based on the accumulation of physical and clinical deficits frailty does not necessarily define end of life. Frailty is bidirectional and with appropriate interventions it can be reversed (Roland et al. 2014). Exercise is likely the medicine that will reverse frailty, at the very least it will slow the accumulation of functional deficits.

Exercise interventions aimed at ultimately reversing the frailty phenotype have a positive functional impact on frail older adults (Roland et al. 2014; Theou et al. 2011). There is strong evidence that exercise improves cardiorespiratory and muscle function, physical activity participation, and functional independence of frail older adults (Theou et al. 2011). Recommendations regarding exercise prescription for frail and pre-frail older adults are proposed 
here (Figure 1), and frequency (days/week), intensity (rating of perceived exertion and \% of 1repetition maximum), duration (minutes/session) and type of exercise are discussed.

Research has not yet conclusively identified the optimal exercise program for reversing frailty (de Labra et al. 2015). In part, this arises from different exercise design interventions, the homogeneity of subjects (age, sex) and how frailty was examined both before and after the intervention. To-date one study has reported a reduction in frailty prevalence following an exercise intervention that targeted walking to achieve $150 \mathrm{~min} /$ week, although it included some lower extremity strength and balance training. However, changes were associated with a reduction in sedentary behavior and not an improvement in fitness (Cesari et al. 2015). A subsequent longer-term (2.6 years) follow-up study was able to prevent the onset of disability and improved recovery from mobility loss (Pahor et al. 2014), unfortunately frailty phenotype was not reported. The current literature is still limited toward demonstrating that exercise will reverse frailty. However, what remains clear is that exercise is the key to preventing physical dependency (Paterson et al. 2004). In order to decisively determine the impact of a specific exercise intervention and its potential to reverse frailty, future research must aim to include frailty assessment tools as an inclusion criteria and an outcome measure to establish what exercise is most effective at reversing frailty (Theou et al. 2011). Here we make recommendations based on the best available current literature for exercise as an effective modality to reverse frailty.

\section{$\underline{\text { Prescription }}$}

Frequency 
A recent systematic review of exercise interventions with pre-frail and frail older adults suggests that the optimal frequency for multi-component (inclusive of aerobic, resistance, balance and flexibility) training is 2-3 times per week (Cadore et al. 2013). Less than 2 times would likely not improve fitness, while greater than 3 times per week may cause some individuals to become over trained and lose interest. Clinicians should aim to progress exercise frequency toward the upper end of the recommended range to facilitate positive behavior modification (longer term exercise adherence) and promote exercise progression (Liu and Fielding 2011).

\section{Intensity}

It is critical that individuals engage in exercise at an intensity that will elicit a fitness benefit by overloading the desired physiological system, causing it to adapt to meet the needs of the exercise demand. For pre-frail and frail older adults aerobic exercise should commence at a moderate intensity (noticeably breathing yet able to participate in verbal conversation) but, eventually progress to a more moderate-vigorous intensity where breathing is more rapid and verbal conversation becomes challenging (Paterson et al. 2007).

More quantifiable measures of intensity include heart rate, the rating of perceived exertion (RPE) scale and percentage of 1-Repetition Maximum (\% 1-RM). Using heart rate as an intensity indicator, Ehsani et al. (2003) demonstrated positive fitness improvements in frail persons walking at $70-75 \%$ of their age-adjusted maximal heart rate. However, clinicians should be aware that many older adults may be using medications that will influence heart rate and should adjust accordingly. Ratings of perceived exertion from 12-14 ("somewhat hard") were reported to be the optimal intensity range for frail and pre-frail adults (Cadore et al. 2013). An RPE of 12- 
14 is equivalent to 3-4 on the category-ratio 10-point (CR-10) RPE scale that is arguably more appropriate for clinical populations including frail and pre-frail older adults (Dawes et al. 2004). Clinicians should aim to have their clients work at the upper end of the RPE scale, or even beyond when appropriate.

Percentage of 1-RM should be used for prescribing intensity of resistance training. Seynnes et al. (2004) concluded that supervised, high-intensity resistance training (80\% of 1-RM) of the kneeextensors appears to be as safe as low-intensity training, while also being more effective. The high-intensity group showed greater improvements from both a physiological and functional perspective (Seynnes et al. 2004). It is hypothesized that the results of Seynnes et al. (2004) could be replicated in other major muscle groups. Clinicians should start their clients with higher repetitions (12-15) and a lower intensity (55\% of 1-RM) in order to build muscular endurance, self-confidence and to master appropriate movement skills. Progressing to fewer repetitions (4-6) at greater intensity $(80 \%$ of $1-\mathrm{RM})$ to maximize muscular strength and functional benefits. Similar to RPE, clients can progress beyond the recommended $80 \%$ when appropriate.

\section{Time}

The optimal duration for each exercise sessions is between 30-45 minutes for frail older adults and 45-60 minutes for pre-frail adults (Theou et al. 2011). Clinicians should adjust the exercise duration to the individual's baseline capacity accordingly. The appropriate duration is dependent on frailty status, age and consistency of exercise participation. Participants must view their training as a long-term commitment as frail older adults can rapidly lose fitness gains upon exercise cessation (Cadore et al. 2014). 
Type

Combining multiple physical conditioning components of exercise has the most profound effect on improving functional capacity, in comparison to interventions that focus upon one form of exercise (Serra-Rexach et al. 2011). A multi-component exercise program is the most effective intervention for improving fitness in frail and pre-frail older adults because frailty impacts multiple physiological systems simultaneously. Using different exercise modalities allows individuals to capitalize on their remaining physiological assets to overcome any deficits. Thus, multi-component exercises for older adults should include elements of resistance, aerobic, balance and flexibility training.

Resistance training in healthy and frail older adults is positively correlated with gains in strength (Latham et al. 2004, Liu and Latham 2009). Resistance training exercises should simulate daily functional tasks, such as the movement of sitting-to-standing (Cadore et al. 2013) and include a variety of both upper and lower body exercises. However, emphasis should be placed on lower body muscles contributing to gross mobility such as knee flexors (hamstrings) and extensors (quadriceps), as well as the gluteal muscles. The preference for lower body exercises can be attributed to the necessity of maintaining physical independence and compensating for greater age-related loss of muscle strength in the lower body compared with upper body (Jakobi et al. 1999, Roos et al. 1997).

Aerobic exercises can include, but are not limited to step-up variations (i.e. marching in-place), stationary cycling and stair climbing using step-platforms with height adjustments to progress the 
aerobic demand as necessary (Jones et al. 2006). However, aerobic work can be as simple as walking, which has shown positive effects in frail adults with dementia (Bherer et al. 2013). Research has demonstrated that a health and fitness benefit can be achieved by increasing the distance walked each day and increasing intensity, which may simply involve reducing the client's use of assistive-walking devices (Cadore et al. 2014). As part of a multi-component program, aerobic exercise should be performed first as it can help elevate the heart rate and prepare clients for the resistance training that is to follow. Clinicians should be aware that even light aerobic work can prove to be difficult for some clients and consider starting with nonweight bearing activities (i.e. stationary bike) when appropriate.

Balance training should include several exercise stimuli such as tandem foot stance, line walking and standing on one leg (Barnett et al. 2003). It is critical that clinicians closely monitor clients during the performance of such exercises, to reduce fall risk. While balance training is important for both pre-frail and frail populations, greater emphasis should be placed on pre-frail individuals, as this population is paradoxically at higher risk for falls as they spend more time walking than frail and thus at greater risk of falling (Mohler et al., 2016). Balance training could be performed after resistance training as part of a cool-down, or integrated within the resistance or flexibility training program.

Flexibility training may also be critical to health and wellness of frail and pre-frail older adults. Similar to balance exercise, flexibility training can be integrated with other modalities of exercise or it can be performed separately as part of the cool-down. Research has demonstrated increases in cadence (steps/min), walking speed $(\mathrm{m} / \mathrm{s})$, stride length and passive hip extension 
range of motion after having frail older adults complete a 10 -week hip flexor stretching routine (Watt et al. 2011). Improving hip range of motion is important as reduced peak hip extension negatively impacts stride length and walking velocity, factors important to gait quality in older adults (Watt et al. 2011). It is hypothesized that similar positive results could be achieved in other major muscle groups through proper stretching interventions. However, a recent systematic review indicated that there is no definitive conclusion on the optimal flexibility program for older adults (Stathokostas et al. 2012).

Strategies for implementation include creating individually tailored multi-component exercise programs administered by exercise specialists to emphasize specific exercise components (aerobic, resistance, balance, flexibility) based on the specific needs of the client. Although not cost- effective or optimal for research, these exercise specialist led programs are most favorable for frail older adults (de Labra et al. 2015). Individually tailored exercise programing highlights the need for exercise specialists to consider progression as a key factor in program success. In healthy older adults, exercise specialists should aim to progress their client's exercise intensity 2$10 \%$, working at the upper and lower end of the intensity spectrum where appropriate (Ratamess et al. 2002). The rate of exercise progression remains largely unknown for frail older adults, but regardless of the frailty status clinicians should closely monitor their client and progress exercises to maximize gains in physiological function that correspond to activities of daily living that promote physical independence. Homebased exercise may complement but not replace a supervised program as unsupervised programs with frail or pre-frail older adults may not be effective (Fairhall et al. 2014). Home exercise for frail older adults, including those who are prefrail or frail, should be weight-bearing and of higher intensity to cause physiological change 
(Latham et al. 2003). Therefore, the client requires sufficient instruction to perform these types of exercises safely and effectively.

Differences in exercise prescription for frail and pre-frail adults are based on the hypothesis that restoring robustness will be most challenging in individuals possessing greater deficits. In frail individuals the exercise training goal may be simply to prevent further regression towards or mitigate frailty status. It is believed that this can be best achieved by placing a greater emphasis on improving aerobic performance. However, pre-frail individuals are at a critical time point, where the training goal is to reverse the frailty phenotype. Thus, the proportion of exercise directed to strength and balance training in pre-frail is higher relative to the frail group in order to promote the return to robust health as well as train elements of function that would reduce the risk for falls. When pre-frail individuals do not take preventative exercise measures to regain strength they may transgress to become frailer and begin a downward spiral of accumulating morbidity.

It is important to recognize that exercise recommendations for frail and pre-frail older adults are different than for older adults who are non-frail or robust. Healthy older adults should follow the physical activity guidelines set forth by the Canadian Society for Exercise Physiology (CSEP, 2012). Exercise guidelines for healthy older adults should include a minimum of 150 minutes of moderate-to-vigorous intensity aerobic exercise per week. Older non-frail adults should also include muscle and bone strengthening activities using major muscle groups, at least two days per week. Pre-frail and frail older adults should aim to meet these guidelines but participation in a multi-component exercise program where pre-frail focus on resistance training, specifically 
lower extremity muscle groups and frail complete relatively longer aerobic exercise session should be the ultimate goal to mitigate frailty (Figure 1).

\section{Conclusion}

Frailty results in a decline in overall quality of life for older adults, causing these individuals to become dependent on others. Additionally, frail older adults are the highest consumers of health care resources, placing a substantial economic burden on the Canadian healthcare system (Buckinx et al. 2015). By reversing frailty through exercise interventions that engender fitness, older adults will remain physically independent and non-frail throughout a longer period of their life. Exercise is the medicine that can prevent frailty as well as reverse it.

\section{Conflict of Interest Statement}

The authors declare no conflict of interest associated with this manuscript. 


\section{$\underline{\text { References }}$}

Barnett, A., Smith, B., Lord, S.R., Williams, M., and Baumand, A. 2003. Community-based group exercise improves balance and reduces falls in at-risk older people: a randomised controlled trial. Age Ageing. 32(4): 407-414. PMID: 12851185

Bherer, L., Erickson, K.I. and Liu-Ambrose, T. 2013. A review of the effects of physical activity and exercise on cognitive and brain functions in older adults. J. Aging Res. Article ID 657508. http://dx.doi.org/10.1155/2013/657508

Buckinx, F., Rolland, Y., Reginster, J.Y., Ricour, C., Petermans, J., and Bruyère, O. 2015. Burden of frailty in the elderly population: perspectives for a public health challenge. Arch. of Public Health. 73(1): 19. doi: 10.1186/s13690-015-0068-X. PMID: $\underline{25866625}$

Cadore, E.L., Moneo, A.B.B., Mensat, M.M., Muñoz, A.R., Casas-Herrero, A., RodriguezMañas, L., et al. 2014. Positive effects of resistance training in frail elderly patients with dementia after long-term physical restraint. Age. 36(2): 801-811. doi: 10.1007/s11357$\underline{013-9599-7}$. PMID $\underline{24243397}$

Cadore, E.L., Rodríguez-Mañas, L., Sinclair, A., and Izquierdo, M. 2013. Effects of different exercise interventions on risk of falls, gait ability, and balance in physically frail older adults: a systematic review. Rejuvenation Res. 16(2): 105-114. doi: 10.1089/rej.2012.1397. PMID: $\underline{23327448}$

Cesari, M., Vellas, B., Fang-Chi, H., Newman, A.B., Doss, H., King, A.C., et al. 2015. A physical activity intervention to treat the frailty syndrome in older persons - results from 
the LIFE_P study. J Gerontol Med Sci. 70(2), 216-222. doi:10.1093/gerona/glu099. PMID: 25387728

Canadian Society for Exercise Physiology. Citing online sources: Canadian Physical Activity Guidelines \& Canadian Sedentary Behaviour Guidelines [online]. Available from: http://www.csep.ca/CMFiles/Guidelines/CSEP_Guidelines_Handbook.pdf [accessed 25 March 2016].

Dawes, H.N., Barker, K.L., Cockburn, J., Roach, N., Scott, O., and Wade, D. 2005. Borg's rating of perceived exertion scales: do the verbal anchors mean the same for different clinical groups? Arch. Phys. Med. Rehabil. 86(5): 912-916. doi:10.1016/j.apmr.2004.10.043

de Labra, C., Guimaraes-Pinheiro, C., Maseda, A., Lorenzo, T., and Millán-Calenti, J.C. 2015. Effects of physical exercise interventions in frail older adults: a systematic review of randomized controlled trials. BMC Geriatri. 15: 154. doi: 10.1186/s12877-015-0155-4

Ehsani, A.A., Spina, R.J., Peterson, L.R., Rinder, M.R., Glover, K.L., Villareal, D.T., et al. 2003. Attenuation of cardiovascular adaptations to exercise in frail octogenarians. J. Appl. Physiol. 95(5): 1781-1788. doi: 10.1152/japplphysiol.00194.2003

Fairhall, N., Sherrington, C., Lord, S.R., Kurrle, S.E., Langron, C., Lockwood, K., et al. 2014. Effect of a multifactorial, interdisciplinary intervention on risk factors for falls and fall rate in frail older people: a randomised controlled trial. Age Ageing. 0: 1-7. doi: 10.1093/ageing/aft204

Fried, L.P., Tangen, C.M., Walston, J., Newman, A.B., Hirsch, C., Gottdiener, J., et al. 2001. Frailty in older adults: evidence for a phenotype. J. Gerentol. A. Biol. Med. Sci. 56A(3): M146-M156. PMID: 11253156 
Hoover, M., Rotermann, M., Sanmartin, C., and Bernier, J. 2013. Validation of an index to estimate the prevalence of frailty among community-dwelling seniors. Health Reports. 24(9): 10-17. PMID: 24258362

Jakobi, J.M., Connelly, D.M., Roos, M.R., Allman, B.L., and Rice, C.L. 1999. Age-related changes of neuromuscular properties in three human limb muscles. In: Taylor, A.W., Ecclestone, N., Jones, G.R., and Paterson, D.H. (Eds.) Proceedings of the First ALCOA National Forum on Older Adults and Active Living. London, ON, pp 111-121, 1999.

Jones, G.R., Jakobi, J.M., Taylor, A.W., Petrella, R.J., and Vandervoort, A.A. 2006. Community exercise program for older adults recovering from hip fracture: a pilot study. J Aging Phys. Act. 14(4): 439-455. PMID: 17215561

Latham, N.K., Anderson, C.S., Lee, A., Bennett, D.A., Moseley, A., Cameron, I.D. 2003. A randomized, controlled trial of quadriceps resistance exercise and vitamin D in frail older people: the frailty interventions trial in elderly subjects (FITNESS). J. Am. Geriatr. Soc. 51(3): 291-299. PMID: 12588571

Latham, N.K., Bennett, D.A., Stretton, C.M., and Anderson, C.S. 2004. Systematic review of progressive resistance strength training in older adults. J. Gerentol. A. Biol. Sci. Med. Sci. 59(1): 48-61. doi:10.1093/gerona/59.1.M48

Liu, C.J., and Latham, N.K. 2009 Progressive resistance strength training for improving physical function in older adults. Cochrane Database Syst. Rev. July 8(3). doi:10.1002/14651858.CD002759.pub2

Liu, C.K. and Fielding, R.A. 2011. Exercise as an intervention for frailty. Clin. Geriatr. Med. 27(1): 101-110. doi:10.1016/j.cger.2010.08.001 
Mohler, M. J., Wendel, C.S., Taylor-Piliae, R.E., Toosizadeh, N., Najafi, B. 2016. Motor performance and physical activity as predictors of prospective falls in communitydwelling older adults by frailty level: Application of wearable technology. Gerontol. [Epub ahead of print] doi:10.1159/000445889

Pahor, M., Guralnik, J.M., Ambrosius, W.T., Blair, S., Bonds, D.E., Church, T.S., et al. 2014. Effect of structured physical activity on prevention of major mobility disability in older adults: the LIFE Study randomized clinical trial. JAMA. 311(23): 2387-2396. doi:10.1001/jama.2014.5616

Paterson, D.H., Govindasamy, D., Vidmar, M., Cunningham, D.A., and Koval, J.J. 2004. Longitudinal Study of Determinants of Dependence in an Elderly Population. J. Am. Geriatr. Res. 52(10): 1632-1638. doi:10.1111/j.1532-5415.2004.52454.x

Paterson, D.H., Jones, G.R., and Rice, C.L. 2007. Aging and physical activity data on which to base recommendations for exercise in older adults. Appl. Physiol. Nutri. Metab. 32 S75S171. PMID:19377547

Ratamess, N.A., Alvar, B.A., Evetoch, T.K., Housh, T.J., Kibler, W.B., Kraemer, W.J., et al. 2002. Progression models in resistance training for healthy adults. Med. Sci. Sports. Exerc. 34(2): 364-380. doi:10.1249/MSS.0b013e3181915670

Rockwood, K., Song, X., MacKnight, C., Bergman, H., Hogan, D.B., McDowell, I., et al. 2005. A global clinical measure of fitness and frailty in elderly people. CMAJ. 173(5): 489-495. doi:10.1503/cmaj.050051

Roland, K.P., Theou, O., Jakobi, J.M., Swan, L., and Jones, G.R. 2014. How do community and occupational therapists classify frailty? A pilot study. J. Frailty \& Aging. 3(4): 247-250. PMID:27048865 
Roos, M.R., Rice, C.L., and Vandervoort, A.A. 1997. Age-related changes in motor unit function. Muscle Nerve. 20(6): 679-690. doi:10.1002/(SICI)10974598(199706)20:6<679::AID-MUS4>3.0.CO;2-5

Serra-Rexach, J.A., Bustamante-Ara, N., Hierro Villarán, M., González Gil, P., Sanz Ibáñez, M.J., Blanco Sanz, N., et al. 2011. Short-term, light-to moderate-intensity exercise training improves leg muscle strength in the oldest old: a randomized controlled trial. J. Am. Geriatr. Soc. 59(4): 594-602. doi:10.1111/j.1532-5415.2011.03356.x

Seynnes, O., Singh, M.A.F., Hue, O., Pras, P., Legros, P., and Bernard, P.L. 2004. Physiological and functional responses to low-moderate versus high-intensity progressive resistance training in frail elders. J. Gerentol. A. Biol. Med. Sci. 59(5): 503-509. doi:10.1093/gerona/59.5.M503

Stathokostas, L., Little, R., Vandervoort, A.A., and Paterson, D.H. 2012. Flexibility training and functional ability in older adults: a systematic review. J. Aging Res. Article ID 306818. doi:10.1155/2012/306818

Theou, O., Stathokostas, L., Roland, K.P., Jakobi, J.M., Patterson, C., Vandervoort, A.A., et al. 2011. The effectiveness of exercise interventions for the management of frailty: a systematic review. J. Ageing Res. Article ID 569194. doi:10.4061/2011/569194

Watt, J.R., Jackson, K., Franz, J.R., Dicharry, J., Evans, J., and Kerrigan, D.C. 2011. Effect of a supervised hip flexor stretching program on gait in frail elderly patients. PM\&R. 3(4) 330-335. doi:10.1016/j.pmrj.2011.01.006 


\section{$\underline{\text { Take Home Points }}$}

1. Older adults can be classified as non-frail, pre-frail or frail. Non-frail should follow the Canadian Physical Activity Guidelines for older adults as a basic exercise recommendation.

2. Pre-frail older adults (exhibit 1-2 physical deficits) should exercise 3 times a week for 45 60 minutes per session. Frail older adults (exhibit $\geq 3$ physical deficits) should exercise 3 times a week but for a shorter duration, 30-45 minutes.

3. Both pre-frail and frail older adults should perform various exercise modalities that includes aerobic, resistance, balance and flexibility activities.

4. However, pre-frail older adults should dedicate (30-40 min), of their training time to resistance and balance training activities while frail older adults should emphasis aerobic training (10-20 $\mathrm{min})$.

5. For aerobic exercise, both pre-frail and frail older adults should work at an intensity that is "moderate-vigorous'," equivalent to a 3-4 (somewhat hard) on the Borg CR-10 point scale. Resistance training intensity is established from individual's 1-RM, starting light (i.e. $55 \%$ ) for beginners and progressing to heavier resistances (i.e. $80^{+} \%$ ).

\section{$\underline{\text { Figure Caption }}$}

Figure 1: Components of exercise prescription. Size of quadrant is proportional to the time dedicated to each exercise modality. It should be noted that each quadrant/modality of exercise does not have to be performed one after another but may be combined with other modalities during the exercise session. This is highlighted by the fact that resistance and balance training share a quadrant and as a result, time (i.e. $40 \mathrm{~min}$ for resistance and balance training for pre-frail older adults). However, the majority of the time (3/4) should be focused upon resistance training. Outer circle on the frail figure identifies the pre-frail total exercise duration. Inner circle and quadrants on the frail figure represents the exercise time accumulated which differs for each component of exercise as well as reduction in total accumulated exercise time. RPE, Rating of Perceived Exertion; 1-RM, One Repetition Maximum; Min, minutes. 

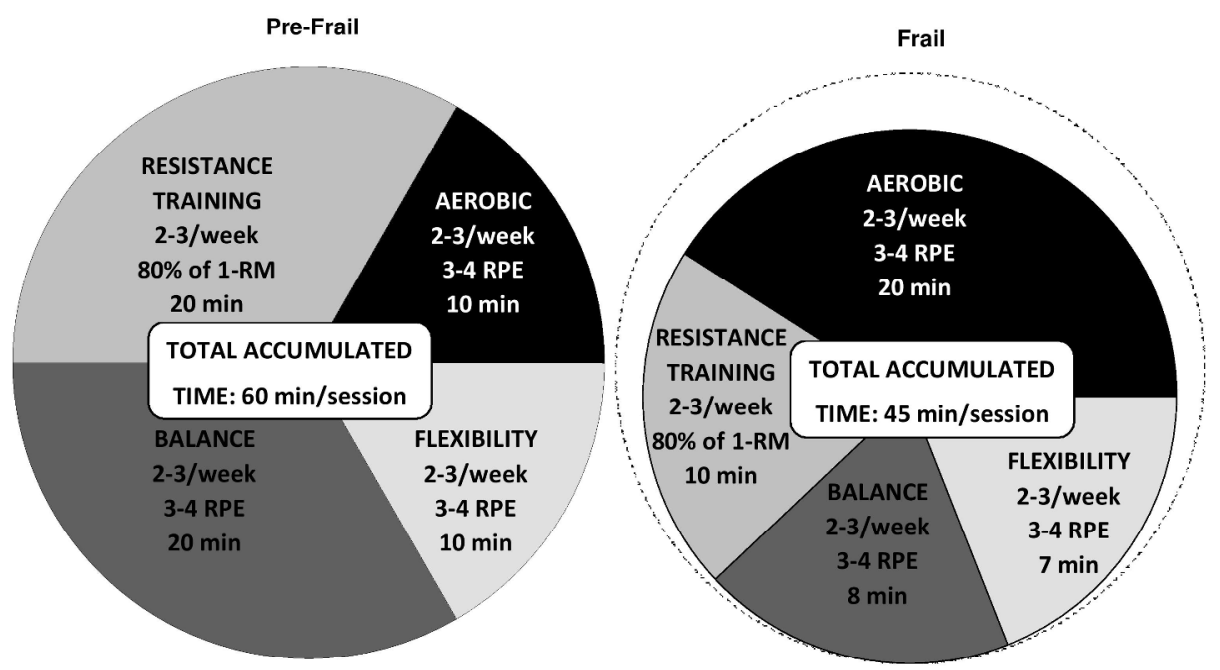

Figure 1: Components of exercise prescription. Size of quadrant is proportional to the time dedicated to each exercise modality. It should be noted that each quadrant/modality of exercise does not have to be performed one after another but may be combined with other modalities during the exercise session. This is highlighted by the fact that resistance and balance training share a quadrant and as a result, time (i.e. 40 min for resistance and balance training for pre-frail older adults). However, the majority of the time (3/4) should be focused upon resistance training. Outer circle on the frail figure identifies the pre-frail total exercise duration. Inner circle and quadrants on the frail figure represents the exercise time accumulated which differs for each component of exercise as well as reduction in total accumulated exercise time. RPE, Rating of Perceived Exertion; 1-RM, One Repetition Maximum; Min, minutes

$279 \times 215 \mathrm{~mm}(300 \times 300 \mathrm{DPI})$ 